\section{Proposta e aplicabilidade de modelo para avaliação da gestão municipal do Programa Nacional de Alimentação Escolar}

\author{
Proposal and applicability of a model to evaluate \\ municipal management of the Brazilian National \\ School Meal Program
}

\author{
Propuesta y aplicabilidad de un modelo para \\ evaluar la gestión municipal del Programa \\ Nacional de Alimentación Escolar
}

${ }^{1}$ Centro de Ciências da Saúde, Universidade Federal de Santa Catarina, Florianópolis, Brasil. 2 Centro de Ciências Biológicas e da Saúde, Universidade Federal de Sergipe, São Cristóvão, Brasil.

Correspondência M. C. M. Calvo Programa de Pós-graduação em Saúde Coletiva, Centro de Ciências da Saúde, Universidade Federal de Santa Catarina.

Campus Universitário Trindades/n,Florianópolis, SC 88040-900, Brasil. mcmcalvo@ccs.ufsc.br

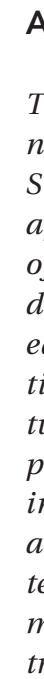 \\ A
Th
ni
Sc
ap
of
du
ed
tion
two
po
in
act
tec
me
}

\section{Abstract}

This article presents a model to evaluate municipal management of the Brazilian National School Meal Program (NSMP) and verifies its applicability in the ten largest cities of the State of Santa Catarina. The model was constructed during workshops with experts and was adapted using the Delphi Method, with participation by 14 collaborators. The model addresses two dimensions of municipal management: the political-organizational dimension, organized in the sub-dimensions resources, inter-sector action, and social control, and the operationaltechnical dimension, which involves the sub-dimensions of nutritional and feeding efficacy, numonitoring, and educational activities for healthy eating. A total of 22 indicators were defined, based on interviews with nutritionists in charge of the NSMP. As for the model's applicability, the indicators appeared feasible with regard to addressing the municipality's responsibilities in the program, and the model should be employed to improve NSMP management at the local level.

Nutrition Policy; School Feeding; Food Security; Program Evaluation
Cristine Garcia Gabriel 1,2

Maria Cristina Marino Calvo 1,2 Roberta Melchioretto Ostermann 1 Francisco de Assis Guedes de Vasconcelos 1

\section{Resumo}

Apresenta-se uma proposta de modelo para avaliar a gestão municipal do Programa Nacional de Alimentação Escolar (PNAE), verificando sua aplicabilidade nos dez municípios de Santa Catarina, Brasil, com mais de 100 mil habitantes. A construção do modelo ocorreu mediante oficinas com especialistas e sua adequação foi realizada por meio do método Delphi, com a participação de 14 colaboradores. O modelo contemplou duas dimensões da gestão municipal: a dimensão político-organizacional, organizada nas subdimensões recursos, atuação intersetorial e controle social, e a dimensão técnico-operacional, que contempla as subdimensões eficácia alimentar e nutricional, monitoramento alimentar e nutricional e atuação pedagógica para a alimentação saudável. No total foram elencados 22 indicadores, coletados por meio de entrevistas com os nutricionistas responsáveis pelo PNAE. Na aplicabilidade os indicadores mostraram-se viáveis para contemplar as atribuições de responsabilidade municipal, devendo o modelo ser futuramente empregado para qualificar a atuação da gestão do PNAE.

Política Nutricional; Alimentação Escolar; Segurança Alimentar e Nutricional; Avaliação de Programas e Projetos de Saúde 


\section{Introdução}

No rol dos programas brasileiros de segurança alimentar e nutricional, destaca-se o Programa Nacional de Alimentação Escolar (PNAE), que reafirma o princípio do Direito Humano à Alimentação Adequada na escola. O PNAE é um dos maiores e mais abrangentes programas de alimentação escolar do mundo, cujo orçamento para 2012 foi de R \$ 3,3 bilhões, beneficiando 45 milhões de estudantes 1 .

Com a descentralização do PNAE em 1993, os recursos federais para sua execução passaram a ser transferidos para entidades executoras e o Programa contou com a inclusão de atores sociais, com destaque para os Conselhos de Alimentação Escolar (CAE). A descentralização possibilitou às entidades executoras realizarem a gestão do PNAE de distintas formas e, em âmbito municipal, a entidade executora é a Secretaria Municipal de Educação (SME) 1,2,3.

Ainda que a trajetória do PNAE seja longa, avaliações com foco na sua gestão pública permanecem escassas 4,5 . Têm predominado na literatura avaliações desenvolvidas na implementação da descentralização 6,7 e avaliações pontuais ou locais, contemplando ações específicas do PNAE 5,8,9. Mais recentemente tem-se observado propostas metodológicas estruturadas em dimensões e indicadores 10,11,12.

Não obstante os inúmeros avanços da avaliação como estratégia para subsidiar a gestão, esta persiste como um campo desafiador, tradicionalmente marcado pela carência de procedimentos sistemáticos 13. Essa experiência é ainda menos significativa em relação aos programas e políticas de segurança alimentar e nutricional, que configuram um campo complexo, multidimensional e interdisciplinar ainda frágil e dependente de abordagens diferenciadas e combinações metodológicas integradoras 14 .

Os programas de segurança alimentar foram avaliados em 45 municípios baianos no período de 1995 a 2002. Os resultados do PNAE foram pouco satisfatórios, possivelmente devido ao processo ainda incipiente de descentralização e participação popular 6. Em outro estudo, os dados de 2004 e 2005 das 670 prefeituras inscritas no Prêmio Gestor Eficiente da Merenda Escolar evidenciaram que o envolvimento de distintos setores da sociedade diferenciou a gestão nas prefeituras vitoriosas 4 .

Em 2004, o Instituto Nacional de Estudos e Pesquisas Educacionais Anísio Teixeira (INEP) inseriu no Censo Escolar questões sobre o PNAE, propondo intensificar a capacitação dos manipuladores de alimentos, integrar as ações do Programa com outros órgãos públicos, qualificar os cardápios e fomentar hábitos saudáveis 15. Como possibilidade de aprofundar um panorama sobre o PNAE, a Associação Brasileira de Nutrição (ASBRAN) realizou em 2007 uma pesquisa em 697 municípios. Essa foi a primeira investigação nacional com esse perfil, contando com o envolvimento de distintos Ministérios, mas seus resultados oficiais ainda não foram divulgados 16 .

O presente trabalho teve como foco as ações de responsabilidade da gestão municipal do PNAE, independente da modalidade de execução do Programa adotada pelo gestor local. O artigo propõe um modelo para avaliar a gestão municipal do PNAE e verifica a sua aplicabilidade nos maiores municípios do Estado de Santa Catarina.

\section{Métodos}

O artigo é oriundo de pesquisa metodológica, com o intuito de desenvolver um modelo avaliativo para a gestão municipal do PNAE, utilizando o método Delphi 17 para adequação da proposta. O modelo foi baseado nos princípios e diretrizes do Programa, estabelecidos pela $L e i$ no 11.947/2009 2 e pela Resolução no 38/2009 3 do Fundo Nacional de Desenvolvimento da Educação (FNDE) e, orientados também pela Lei no 11.346/2006 (Lei Orgânica de Segurança Alimentar e Nutricional - LOSAN) 18 (Figura 1).

As dimensões, subdimensões e indicadores do modelo foram obtidos por meio de oficinas com especialistas dos campos da alimentação e nutrição e de avaliação de políticas públicas. Na primeira oficina, de 16 horas, 11 participantes validaram o referencial teórico da pesquisa e definiram as ações de gestão direcionadas ao ensino fundamental como foco do modelo. $\mathrm{Na}$ segunda oficina, de oito horas, o modelo foi delineado quanto às dimensões, subdimensões e respectivas justificativas teóricas. Previamente, realizou-se em 2010 uma revisão da literatura tradicional com a finalidade de localizar estudos empíricos com indicadores de avaliação do PNAE. A busca ocorreu nas bases MEDLINE, LILACS e SciELO Brasil. Os descritores utilizados foram: "alimentação escolar"; "Programa Nacional de Alimentação Escolar"; "PNAE”; "política de alimentação escolar"; e "segurança alimentar e nutricional”. Essa revisão resultou em uma lista de indicadores utilizados em outros estudos, que foram complementados por sugestões de novos indicadores propostos pelos especialistas. Essa lista foi discutida até que se atingisse consenso. Posteriormente, foram elencados os itens a serem observados na gestão do PNAE (medidas), visando a mensurar os resultados e contemplar 
Modelo teórico-lógico do Programa Nacional de Alimentação Escolar (PNAE), com base nas decisões tomadas pelo gestor público municipal. Brasil, 2012.

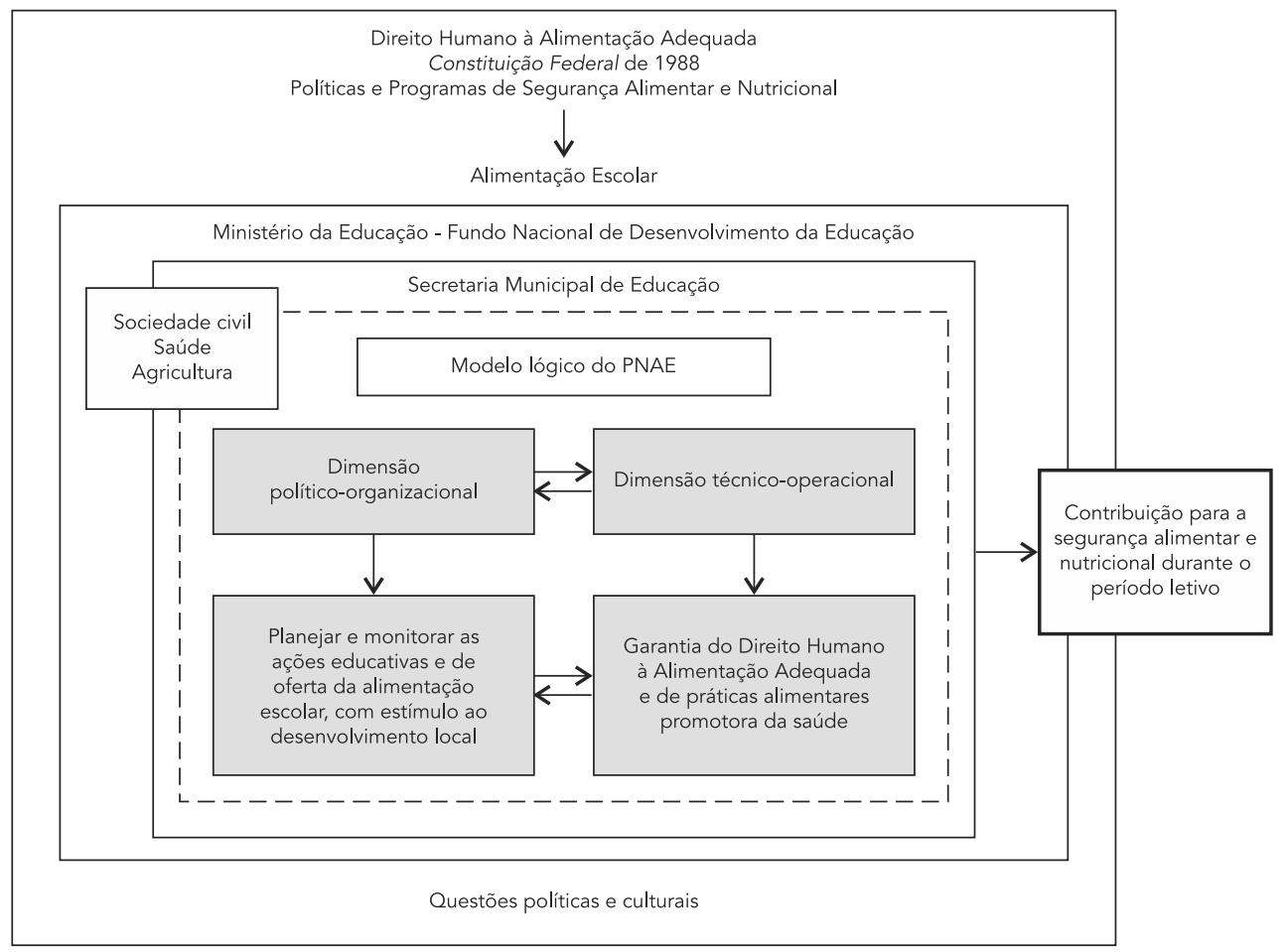

as justificativas teóricas de cada indicador. $\mathrm{Na}$ sequência foi elaborado o questionário de coleta de dados.

A próxima etapa foi de adequação e validação do modelo pelo método Delphi, que possibilita a avaliação prospectiva e consensual por especialistas, sem contato presencial e com anonimato entre os participantes 17 .

A identificação dos especialistas ocorreu via levantamento de pesquisadores na Plataforma Lattes do Conselho Nacional de Desenvolvimento Científico e Tecnológico (CNPq) e levantamento dos artigos publicados na base de dados SciELO Brasil, que tivessem como objeto de estudo o PNAE e a segurança alimentar e nutricional. Em ambas as bases os unitermos utilizados foram: "segurança alimentar e nutricional". "avaliação de políticas públicas”; "alimentação escolar"; "programas e políticas de nutrição e alimentação"; e "direito humano à alimentação adequada”.

Foram selecionados profissionais com publicações em periódicos e/ou livros nos últimos três anos (janeiro de 2008 a março de 2011) e/ ou com participação atual em projetos/pesquisas relacionadas à temática. Essa busca resultou em 16 profissionais. Foram também elencados os Coordenadores de Gestão dos oito Centros Colaboradores em Alimentação e Nutrição Escolar (CECANEs) em funcionamento na época e os atores que ocupavam, respectivamente, os cargos de coordenação e presidência do PNAE e do Conselho Nacional de Segurança Alimentar e Nutricional (CONSEA). Como a maioria desses já havia aparecido na busca anterior, somente três novos nomes foram acrescentados, totalizando 19 especialistas, que foram convidados a participar da pesquisa, devendo acessar o website do projeto e preencher o Termo de Consentimento Livre e Esclarecido.

Na primeira solicitação os especialistas receberam o modelo avaliativo contendo as justificativas teóricas de cada dimensão, subdimensão e indicadores propostos, bem como as questões que seriam coletadas. Para cada um desses componentes solicitou-se uma avaliação quanti-qua- 
litativa, numa escala crescente de adequação de 1 a 10. Dentre os 19 colaboradores, 14 enviaram sugestões nessa primeira etapa. Dos 29 itens avaliados, 16 (55\%) receberam notas $\geq 9$; $12(41,5 \%)$ receberam notas entre 7 e 9 e um item (3,5\%) recebeu pontuação inferior a 7. Os comentários e contribuições foram incorporados ao material sempre que consonantes ao objetivo e justificativa teórica do modelo. Após os primeiros ajustes, o instrumento foi reenviado aos participantes. Nesse segundo momento, 9 dos 14 participantes enviaram novas sugestões que passaram pelo mesmo processo, resultando na aprovação final do instrumento. Uma última oficina foi realizada para finalizar a proposta.

Verificou-se a aplicabilidade do modelo por meio de estudo de casos múltiplos nos $10 \mathrm{mu}$ nicípios de Santa Catarina com mais de 100 mil habitantes (Instituto Brasileiro de Geografia e Estatística. Contagem da População 2007. http:// www.ibge.gov.br/home/estatistica/populacao/ contagem2007/contagem.pdf. acessado em 01/ Dez/2012), elencados independentemente da modalidade de gestão do PNAE. A priorização pelos municípios de maior porte reflete a intenção de se investigar casos de maior complexidade na gestão pública. Todavia, não implica prejuízos em futuras aplicações e análises provenientes do modelo para municípios menores.

Os secretários municipais de educação foram convidados a participar da pesquisa, sendo realizada uma visita aos municípios para esclarecimentos. A avaliação é direcionada aos gestores do Programa, e todos os municípios remeteram a responsabilidade pelas respostas para os nutricionistas do PNAE. Tal fato pode ser compreendido, uma vez que a legislação do Programa destaca esse profissional como responsável técnico pela sua execução ${ }^{2}$. O questionário utilizado foi submetido a pré-teste em município catarinense com características populacionais similares e, entre fevereiro e outubro de 2012, foram agendadas visitas para entrevista estruturada e coleta dos dados documentais locais (documentos do CAE e formulários de prestação de contas). Os dados coletados foram relativos ao ano anterior à execução do Programa (2011). As entrevistas foram gravadas e transcritas.

A aplicabilidade do modelo foi verificada no conjunto dos casos por meio de descrição da aplicação do instrumento e, consequentemente, dos dados provenientes dos indicadores e itens observados. A principal análise nessa etapa foi a facilidade ou a dificuldade na obtenção dos dados. Considerou-se "dificuldade" a ausência ou não fornecimento dos dados, e ainda o desconhecimento dos mesmos pelo respondente ou sua equipe. A descrição apresentada tem o intuito de verificar a consistência dos dados em relação aos indicadores e não objetiva consolidar a avaliação propriamente dita. Para o presente modelo, consideraram-se todos os indicadores com o mesmo grau de importância. A identificação de deficiências em determinados indicadores pode ser realizada na análise de cada subdimensão, possibilitando a adequação do modelo para futuras aplicações.

Este artigo é parte de uma pesquisa de maior extensão (Edital MCT-SECIS/CNPq no 019/2010 - processo no 559328/2010-9) aprovada pelo Comitê de Ética em Pesquisa da Universidade Federal de Santa Catarina (processo no 1143 de 29/ Nov/2010).

\section{Resultados e discussão}

\section{Desenvolvimento do modelo}

A execução do PNAE pela SME foi interpretada com base em duas dimensões. A dimensão político-organizacional pressupõe que existem ações de gestão externas à execução do PNAE nas escolas. Contempla as áreas em que o gestor deve atuar para que o PNAE atinja seus objetivos, tendo como eixo central a intersetorialidade, que deve permear desde as ações de planejamento até a avaliação e monitoramento. Em âmbito municipal, o gestor deve garantir o acesso universal, equânime, regular e contínuo à alimentação saudável; apoiar o desenvolvimento sustentável e o controle social; promover o resgate dos hábitos alimentares regionais; planejar e monitorar as ações de oferta da alimentação e as ações de educação alimentar e nutricional.

A segunda dimensão é a técnico-operacional, que descreve as responsabilidades decorrentes da gestão que devem acontecer especificamente na escola, sendo basilares para a garantia do direito humano à alimentação adequada e de práticas alimentares promotoras da saúde. A gestão deve garantir a eficácia no fornecimento de refeições e nas ações de educação alimentar e nutricional, monitorando os estudantes sob sua responsabilidade. Entende-se eficácia como a habilidade do gestor em tomar decisões para o atendimento das normativas do PNAE. Essa dimensão objetiva demonstrar o comprometimento da gestão com a função pedagógica do Programa.

A partir disso, o modelo resultou em duas dimensões, seis subdimensões e 22 indicadores (Tabela 1), listados nas Tabelas 2 e 3 com os itens observados em cada um deles e os respectivos parâmetros de julgamento. Tais parâmetros foram fundamentados em aspectos normativos, revisão da literatura e consenso entre especialistas. 


\section{Tabela 1}

Dimensões, subdimensões e número de indicadores do modelo avaliativo da gestão municipal do Programa Nacional de Alimentação Escolar.

\begin{tabular}{lcc}
\hline Dimensões & Subdimensões & Indicadores \\
\hline Político-organizacional & Recursos & 8 \\
& Atuação intersetorial & 3 \\
& Controle social & 3 \\
Técnico-operacional & Eficácia alimentar e nutricional & 4 \\
& Monitoramento alimentar e nutricional & 2 \\
Total & Atuação pedagógica para a alimentação saudável & 2 \\
\hline
\end{tabular}

Tabela 2

Indicadores, itens observados e respectivos parâmetros de julgamento da dimensão político-organizacional da gestão municipal do Programa Nacional de Alimentação Escolar (PNAE)

Indicadores - Itens observados

Subdimensão Recursos

1. Participação da Entidade Executora na execução financeira do PNAE Relação de investimento em alimentos SME/FNDE Utilização do recurso federal (saldo anual)

2. Adequação do quadro de nutricionistas Relação nutricionista/escolar (número de horas de trabalho de nutricionistas disponibilizadas pelo município em conformidade com normativa do CFN)

3. Adequação da equipe de produção das refeições Relação refeições/manipuladores de alimentos Execução pelos manipuladores de alimentos de atribuições extras ao PNAE

4. Qualificação do profissional Existência na SME de programa de formação introdutório para novos manipuladores Quantitativo de manipuladores formados nos últimos dois anos

5. Condições para o trabalhador

$\%$ de itens atendidos (nutricionistas):

a) Adequação do salário base ao piso nacional

b) Existência de plano de saúde

c) Existência de plano de carreira

d) Recebimento de vale refeição

$\%$ de itens atendidos (manipuladores):

a) Existência de plano de saúde

b) Existência de plano de carreira

c) Recebimento de vale refeição

d) Recebimento de vale transporte
Parâmetro do item observado

$>50 \%$ : bom; $30-50 \%$ : regular; < 30\%: ruim

< 10\%: bom; $10-20 \%$ : regular; > 20\%: ruim

Sim: bom; Não: ruim

< 100/1: bom; 100-150/1: regular; > 150/1: ruim

Sim: ruim; Não: bom

Sim: bom; Não: ruim

100\%: bom; 75-99\%: regular; < 75\%: ruim

$\geq 75 \%: 3$ ou 4 sim - bom

< 75\%: 1 ou 2 sim - ruim

$\geq 75 \%$ : 3 ou 4 sim - bom

$<75 \%$ : 1 ou 2 sim - ruim

(continua) 
Tabela 2 (continuação)

Subdimensão Recursos

6. Condição para o trabalho

$\%$ de itens atendidos (nutricionistas):

a) Existência de sala de trabalho adequada

b) Existência de softwares computadores adequados

c) Existência de equipamentos de avaliação nutricional em número suficiente e em bom estado de conservação

d) Disponibilidade adequada de locomoção para realização de atividades técnicas

e) Disponibilidade de materiais educativos para realização de práticas educativas

$\%$ de itens atendidos (manipuladores):

a) Disponibilidade de uniformes em quantidade e qualidade adequadas

b) Disponibilidade de Equipamentos. de Proteção Individual

c) Existência de normas de gestão para realização de exames médicos periódicos

7. Condições adequadas para o armazenamento e preparo dos alimentos

Existência de manual de boas práticas nas escolas

Existência de procedimentos operacionais padronizados nas escolas

Existência de fichas técnicas das preparações para os cardápios

8. Local adequado para as refeições

Quantidade de escolas com refeitórios em condições adequadas para receber os alunos Subdimensão Atuação Intersetorial

1. Articulação do PNAE com o setor saúde

Existência de projeto/programa realizado pela gestão do PNAE em conjunto com a SMS

2. Relação escolas vs. UBS

Existência de rotina de encaminhamento de escolares diagnosticados na escola em risco nutricional para UBS

3. Estímulo ao desenvolvimento regional para a produção de alimentos

Utilização do recurso federal com a agricultura familiar

Realização de ações que incentivaram a entrada de produtores regionais no PNAE

Subdimensão Controle Social

1. Regularidade da atuação do controle social

Número de reuniões com quórum mínimo realizadas pelo $\mathrm{CAE}$, com registro em ata

2. Perfil da atuação do CAE

Presença de registro em atas ou em outros documentos de discussões sobre:

a) Visita a, no mínimo, uma escola por mês

b) Cardápios do PNAE

c) Compra da agricultura familiar e do empreendedor familiar rural ou suas

organizações

d) Situação alimentar e nutricional dos alunos

e) Condições de preparo e oferta da alimentação

f) Execução financeira do PNAE, ao longo do ano

g) Pontos frágeis na execução do PNAE, registrados no parecer conclusivo do CAE

Potencial de deliberação:

a) Existência de deliberação do $C A E$, registrada em ata

b) Implementação de deliberação do CAE

3. Apoio institucional ao controle social

$\%$ de itens disponibilizados aos membros do CAE:

a) Local apropriado para reuniões

b) Equipamento de informática

c) Transporte para deslocamento

d) Recursos humanos para apoiar o CAE
<75\%: 1, 2 ou 3 sim - ruim

$\geq 75 \%: 3 \mathrm{sim}$ - bom

< 75\%: 1 ou 2 sim - ruim

Sim: bom (2); Não: ruim

Sim: bom (2); Não: ruim

Sim: bom (2); Não: ruim

100\%: bom; $75-99 \%$ : regular; $<75 \%$ : ruim

Sim: bom; Não: ruim

Sim: bom; Não: ruim

$\geq 30 \%$ : bom; $20-29 \%$ : regular; < $20 \%$ : ruim Sim: bom; Não: ruim

$\geq 10$ reuniões: bom; 7-9: regular; $<7$ : ruim

$\geq 75 \%$ : 6 ou 7 sim - bom

$<75 \%$ : $\leq 5 \mathrm{sim}$ - ruim

$\geq 75 \%: 2 \mathrm{sim}-$ bom

$<75 \%$ : $1 \mathrm{sim}$ - ruim

$\geq 75 \%$ : 3 ou 4 sim - bom

$<75 \%$ : 2 ou $1 \mathrm{sim}$ - ruim

CAE: Conselho de Alimentação Escolar; CFN: Conselho Federal de Nutricionistas; FNDE: Fundo Nacional de Desenvolvimento da Educação; SME: Secretaria Municipal de Educação; SMS: Secretaria Municipal de Saúde; UBS: Unidades Básicas de Saúde. 
Indicadores, itens observados e respectivos parâmetros de julgamento da dimensão técnico-operacional da gestão municipal do Programa Nacional de Alimentação Escolar (PNAE).

\section{Indicadores - Itens observados}

\section{Parâmetro do item observado}

Subdimensão Eficácia Alimentar e Nutricional

1. Adequação da oferta

Orientação padronizada sobre o porcionamento a cada mudança de cardápio Inclusão diária de frutas ou hortaliças nos cardápios

Frequência mensal de alimentos que devem ser controlados no cardápio (salsicha/linguiça, margarina, achocolatado e pudim/creme doce)

Realização de cálculo dos valores nutricionais dos cardápios planejados

Realização de orientações para os alimentos comercializados nas cantinas

2. Respeito à cultura alimentar saudável

Inserção de alimentos/preparações locais/regionais nos cardápios

Atendimento diferenciado e adequado para povos e comunidades tradicionais (indígenas e quilombolas)

Realização de investigação sobre os hábitos alimentares dos escolares

3. Execução do cardápio

Existência de sistema de controle sobre as substituições de cardápios realizadas nas escolas

Prejuízo do equilíbrio nutricional com as substituições de cardápios

Problemas com licitação que prejudicou o cumprimento de um cardápio adequado

Existência de sistema de controle sobre o número de refeições/dia/escola

4. Adequação dos cardápios para escolares que necessitam de atenção específica

Existência de cardápios adequados para atender a cada grupo de escolares com necessidades nutricionais especiais

Subdimensão Monitoramento Alimentar e Nutricional

1. Vigilância nutricional dos escolares

Existência de dados de avaliação do estado nutricional dos escolares com periodicidade no mínimo anual

Cobertura de escolares avaliados (peso e altura)

Utilização das informações de avaliação nutricional no planejamento do PNAE

2. Supervisão do nutricionista

Periodicidade mensal das visitas por escola, sob responsabilidade da equipe técnica de nutrição

Periodicidade mensal do acompanhamento do porcionamento das refeições nas escolas, sob responsabilidade da equipe técnica de nutrição

Subdimensão Atuação Pedagógica para a Alimentação Saudável

1. Ações de estímulo à educação alimentar e nutricional

Existência de projetos e/ou atividades educativas abrangentes, estimulados pela SME na área de alimentação escolar e direcionados aos escolares

Quantitativo de escolas que desenvolvem atividades práticas regulares de incentivo à alimentação saudável

2. Transversalidade do tema alimentação saudável Inserção do tema alimentação saudável no currículo

Capacitação de professores para trabalhar o tema alimentação saudável no currículo
Sim: bom; Não: ruim

Sim: bom; Não: ruim

$\leq 4$ vezes/mês: bom; 5-7: regular; $\geq 8$ : ruim

Sim: bom; Não: ruim

Sim: bom; Não: ruim

Sim: bom; Não: ruim

Sim: bom; Não: ruim

Sim: bom; Não: ruim

Sim: bom; Não: ruim

Sim: ruim; Não: bom

Sim: ruim; Não: bom

Sim: bom; Não: ruim

Sim: bom; Não: ruim

Sim: bom; Não: ruim

100\%: bom; 80-99\%: regular; $\leq 79 \%$ : ruim

Sim: bom; Não: ruim

Sim: bom; Não: ruim

Sim: bom; Não: ruim

Sim: bom; Não: ruim

100\%: bom; 75-99\%: regular; $\leq 74 \%$ : ruim

Sim: bom; Não: ruim

Sim: bom; Não: ruim

SME: Secretaria Municipal de Educação. 
Na Tabela 2, observam-se os componentes da dimensão político-organizacional. A subdimensão Recursos refere-se ao compromisso do gestor com recursos financeiros compatíveis com o PNAE; profissionais qualificados, em quantidade apropriada, de forma continuada e com condições satisfatórias para o trabalho; e locais de produção e fornecimento de refeições adequadas às boas práticas para serviços de alimentação. Nessa subdimensão foram incluídos oito indicadores: (1) participação da entidades executoras na execução financeira do PNAE - avalia o esforço do gestor em investir nos alimentos do Programa, não restringindo a compra destes ao repasse complementar do FNDE 2,3; (2) adequação do quadro de nutricionistas - pressupõe que o cumprimento dos parâmetros mínimos para nutricionistas estabelecidos pela Resolução no 465/2010 do Conselho Federal de Nutricionistas (CFN) 19 é indicativo da importância que o gestor confere ao PNAE e fator sugestivo de melhor execução do mesmo; (3) adequação da equipe de produção das refeições - dispõe que o gestor deve assegurar o número adequado de manipuladores de alimentos, evitando sobrecargas e prejuízos à saúde dos trabalhadores e à qualidade das refeições. Mesmo com a inexistência de parâmetros quantitativos específicos para o PNAE 2,3,19, o indicador deve ser avaliado com base em regulamentações afins; (4) qualificação do profissional - dispõe sobre a necessidade da constante qualificação dos profissionais; (5) condições para o trabalhador e (6) condições para o trabalho - pressupõem sobre a necessidade da gestão oferecer condições adequadas de trabalho para nutricionistas e manipuladores de alimentos 20; (7) condições adequadas para armazenamento e preparo dos alimentos e (8) local adequado para as refeições - pressupõem que a gestão deve promover ações de infraestrutura e saneamento básico nas escolas 2,3,21, garantindo locais adequados e refeições em condições apropriadas.

A subdimensão Atuação Intersetorial (Tabela 2) reforça a intersetorialidade como conceitochave das políticas e programas de segurança alimentar e nutricional 22. A gestão do PNAE deve se articular com outros setores responsáveis pela segurança alimentar e nutricional dos escolares, visando a parcerias e corresponsabilização. Nela foram incluídos três indicadores: (1) articulação do PNAE com o setor saúde - considerada ação estratégica por parte da gestão do Programa ${ }^{3,23}$. Um exemplo seria a adesão dos municípios ao Programa Saúde na Escola (PSE) 24; (2) relação escolas vs. unidades básicas de saúde (UBS) - pressupõe que a escola deve encaminhar escolares para UBS e estas devem fazer a contrarreferência, qualificando as ações de vigilância e monitoramento, e contribuindo também para a integralidade no Sistema Único de Saúde; (3) estímulo ao desenvolvimento regional para a produção de alimentos - dispõe que a gestão deve fomentar o desenvolvimento regional 2,3, indicando comprometimento com a economia local e com a alimentação escolar.

A subdimensão Controle Social (Tabela 2) é respaldada pelas normativas do PNAE que dispõem sobre o CAE 2,3. Nessa subdimensão foram incluídos três indicadores: (1) regularidade da atuação do controle social - parte da premissa de que quanto maior o número de reuniões do CAE, maior a sua participação na implementação do PNAE. Considerando que o CAE tem sete titulares, são adequadas reuniões com pelo menos quatro titulares (50\%). Entende-se que deliberações tomadas por um quantitativo inferior ao quórum mínimo não expressam o efetivo controle social; (2) perfil de atuação do CAE pressupõe que a plena execução das ações do CAE requer visitas regulares às escolas, discussões organizadas que extrapolem a prestação de contas e deliberações frente às necessidades do PNAE; (3) apoio institucional ao controle social - compete à gestão garantir ao CAE infraestrutura e recursos necessários à execução de suas atividades 2,3.

A Tabela 3 apresenta a dimensão técnicooperacional. A subdimensão Eficácia Alimentar e Nutricional trata do compromisso do gestor com o planejamento e acompanhamento dos cardápios. Nessa subdimensão foram incluídos quatro indicadores: (1) adequação da oferta dispõe que o nutricionista deve elaborar cardápios com base no diagnóstico e referências nutricionais, respeitando idade e hábitos locais 2,3,19. Ainda, a gestão deve garantir a qualidade de todos os alimentos oferecidos durante o período letivo, independentemente da origem 2; (2) respeito à cultura alimentar saudável - corroborando com o Guia Alimentar para a População Brasileira 25, o PNAE tem como premissa promover hábitos regionais saudáveis 2,3,19. A oferta de alimentos regionais contribui para concretizar essa recomendação; (3) execução do cardápio dispõe que a gestão deve garantir o direito do escolar à alimentação adequada por, no mínimo, 200 dias letivos. Considera-se esse direito garantido quando se realiza a oferta regular dos alimentos/preparações planejados pela equipe de nutrição. Substituições no cardápio que acarretem em prejuízo nutricional não concretizam a plena execução do Programa; (4) adequação dos cardápios para escolares que necessitam de atenção específica - dispõe que os cardápios devem oferecer uma alimentação variada, saudável e 
adequada, de acordo com o estado de saúde dos escolares 2,3,19.

A subdimensão Monitoramento Alimentar e Nutricional (Tabela 3) foi elencada, pois consiste em importante estratégia para subsidiar as políticas de segurança alimentar e nutricional 14,23,24. As normativas do PNAE referem que compete à equipe de nutrição coordenar o diagnóstico e monitoramento nutricional dos estudantes 2,3,19. Em Santa Catarina, a Lei no 15.265/2010 26 instituiu o Programa de Prevenção e Tratamento da Obesidade Infantil, que dispõe sobre a obrigatoriedade das escolas em realizar avaliação física dos alunos entre 7 e 14 anos, a cada seis meses. Nessa subdimensão foram incluídos dois indicadores: (1) vigilância nutricional dos escolares pressupõe que a existência e utilização de dados relativos à situação nutricional dos escolares no planejamento do PNAE são indicativos de comprometimento da gestão com a saúde escolar 2,3; (2) supervisão do nutricionista - as normativas do PNAE elencam muitas atribuições ao nutricionista 2,3,19, demandando supervisão direta nas unidades. A gestão deve assegurar o número apropriado de profissionais e os mesmos devem ter condições adequadas para realizar visitas periódicas às escolas.

A subdimensão Atuação Pedagógica para a Alimentação Saudável (Tabela 3) trata do compromisso do gestor com a promoção de educação alimentar e nutricional nas escolas ${ }^{3}$. Nela foram incluídos dois indicadores: (1) ações de estímulo à educação alimentar e nutricional - pressupõe que a iniciativa da SME em estimular, implementar e/ou coordenar atividades e projetos educativos em alimentação e nutrição, direcionados aos escolares, sugere comprometimento com a função do PNAE. Além disso, a gestão deve incentivar e monitorar a realização de atividades práticas de incentivo à alimentação saudável nas escolas; (2) transversalidade do tema alimentação saudável - pressupõe que a gestão observe a diretriz do PNAE que se refere à inclusão da educação alimentar e nutricional no processo de ensino e aprendizagem ${ }^{3}$, propondo oficialmente a inclusão do tema no currículo e monitorando esta atividade.

\section{Aplicabilidade do modelo}

Dentre os 10 municípios, três tinham gestão terceirizada do PNAE e um gestão mista. Os outros seis tinham gestão centralizada, entretanto, dois contavam com histórico de terceirização, um terceirizava mão de obra e um possuía cozinha centralizada. Apesar de serem todos municípios com mais de 100 mil habitantes, observou-se grande variação em ter- mos populacionais e educacionais. A média populacional dos municípios foi de 245.174 $(\mathrm{dp}=128.913)$; com média de $46(\mathrm{dp}=19,5)$ escolas básicas e $15.854(\mathrm{dp}=11.312)$ escolares matriculados no ensino fundamental em 2011.

\section{Subdimensão Recursos}

Quanto ao primeiro indicador - participação das entidades executoras na execução financeira do PNAE - em dezembro de 2012 somente cinco casos haviam finalizado e disponibilizado a prestação de contas relativa a 2011. Esse fato decorreu de o FNDE ter implantado mudanças na prestação de contas em 2012, acarretando atrasos no preenchimento do formulário financeiro dos municípios. Além disso, em 4 dos 5 casos foram encontradas inconsistências nos dados financeiros e/ou campos de preenchimento obrigatório em branco e/ou preenchidos erroneamente. Nos dois casos analisados com gestão terceirizada não havia discriminação de modalidades de educação atendida pelo PNAE ou não havia diferenciação entre gestão centralizada e terceirizada (modalidade mista). Apesar dessas dificuldades, esse indicador deve ser mantido no modelo, tendo em vista sua relevância na gestão pública e o caráter pedagógico que pode assumir caso seja monitorado adequadamente.

Com relação ao segundo indicador - adequação do quadro de nutricionistas - o item observado (número de horas de trabalho de nutricionistas) foi de fácil entendimento, porém influenciado pela modalidade de gestão do PNAE. Nos cinco casos em que havia algum tipo de terceirização, deparou-se com dificuldade na obtenção do dado.

Esse fato repetiu-se no terceiro indicador adequação da equipe de produção das refeições - no qual somente sete municípios forneceram dados numéricos de manipuladores. Todavia, esses dados nem sempre abarcavam todos os manipuladores em exercício, uma vez que este cargo muitas vezes não existia e a gestão não tinha domínio das funções exercidas e/ou dos funcionários terceirizados. Ainda no terceiro indicador, para o item execução pelos manipuladores de alimentos de atribuições extras ao PNAE, observou-se pouco controle nas gestões centralizadas, indicando sua manutenção para melhorar o controle por parte da gestão pública, que deve desenvolver ferramentas para sistematizar seus dados e evitar prejuízos à saúde dos trabalhadores. Esse indicador merece atenção, principalmente ao se considerar que estudos com manipuladores de alimentos do PNAE indicam condições de atuação precarizadas 27 e percepções de desvalorização por parte destes atores 28 . 
Os próximos indicadores (quarto - qualificação do profissional, quinto - condições para o trabalhador e sexto - condições para o trabalho) foram influenciados pelo tipo de execução do PNAE. Nos casos terceirizados, a gestão recorria à empresa e nem sempre o dado retornava com a completude solicitada (somente sete casos disponibilizaram dados de manipuladores relativos aos indicadores quinto e sexto). Especificamente no quinto indicador, dois dos itens observados no checklist não foram discriminatórios, a saber: recebimento de vale refeição e recebimento de vale transporte. Os demais itens foram variáveis para os casos. Como exemplo, cita-se o piso salarial de nutricionistas, considerado defasado pela categoria 29, e motivo de descontentamento entre profissionais da área 30 . Superar as deficiências do trabalho dos manipuladores e nutricionistas constitui estratégia vital para alcançar os objetivos do PNAE 27,28,30.

Os itens observados nos indicadores sétimo (condições adequadas para armazenamento $e$ preparo dos alimentos) e oitavo (local adequado para as refeições) mostraram-se coerentes com seus objetivos. Entretanto, no oitavo indicador, o item quantitativo de escolas com refeitórios em condições adequadas para receber os alunos não atingiu as expectativas, uma vez que seis casos não souberam precisar. Apesar disso, o item será mantido, pois a gestão deve estar a par dessa informação para poder planejar a adequação estrutural de suas unidades. Reforçando a importância desse indicador, pesquisa em escolas de Salvador (Bahia) encontrou condições higiênicosanitárias inadequadas, sugerindo ajustes nos estabelecimentos 31 .

\section{Subdimensão Atuação Intersetorial}

Os dois primeiros indicadores - articulação do PNAE com o setor saúde e relação escolas vs. UBS - foram bem compreendidos, embora a maioria dos casos tenha apresentado baixo desempenho nos itens. Apesar disso, os indicadores permanecerão no modelo, tendo em vista a importância dessas ações. O terceiro indicador - estímulo ao desenvolvimento regional para a produção de alimentos - foi parcialmente prejudicado, pois seu primeiro item observado (utilização do recurso federal com a agricultura familiar) dependia da prestação de contas de 2011, concluída em apenas metade dos casos. O segundo item (realização de ações que incentivaram a entrada de produtores regionais no PNAE) mostrou potencial para diferenciar a gestão. A comercialização de gêneros para o PNAE é um processo relativamente novo e complexo para muitos agricultores e municípios, colocando a gestão do PNAE em posição estratégica no apoio à entrada e permanência do pequeno produtor no Programa 32.

\section{Subdimensão Controle Social}

Os dois primeiros indicadores - regularidade da atuação do controle social e perfil de atuação do $C A E$ - dependiam de atas e outros documentos dos conselhos de alimentação escolar, disponibilizados por todos os municípios. O formato e conteúdo dos documentos dos conselhos de alimentação escolar nem sempre possibilitaram a obtenção da informação desejada, especialmente quanto ao segundo indicador, ao tratar do potencial de deliberação do CAE, complementado por meio de entrevista com os respondentes. O questionamento nem sempre foi de fácil entendimento e/ou as respostas foram pouco precisas. Apesar dessas dificuldades, considera-se que o item deve ser mantido e sua aplicação pode resultar em maior atenção ao caráter deliberativo do Conselho. No terceiro indicador - apoio ins titucional ao controle social - o primeiro item do checklist (local apropriado para reuniões) não foi discriminatório, diferentemente dos outros três itens que mostraram maior variação.

\section{Subdimensão Eficácia Alimentar e Nutricional}

O primeiro indicador - adequação da oferta - foi composto por cinco itens. O primeiro (orientação sobre o porcionamento) foi de difícil aferição nas gestões centralizadas, nas quais isto não acontecia de forma sistematizada, embora constitua premissa do PNAE 3. Os segundo item (inclusão diária de frutas ou hortaliças nos cardápios) foi facilmente compreendido. Os cardápios do PNAE devem oferecer, pelo menos, três porções de frutas/hortaliças por semana (200g/semana) 3 . Na presente proposta julgou-se adequado que a gestão garanta esses alimentos diariamente 25 , considerando que as refeições devem assegurar seu papel pedagógico e promotor de saúde. O terceiro item (frequência mensal de alimentos que devem ser controlados no cardápio) ficou na dependência dos cardápios, que eram de difícil análise, pois não continham informações completas sobre as preparações. Ainda com relação ao terceiro item, o PNAE restringe a aquisição de alimentos com alto teor de gordura e sódio 3 . Utilizando como base o método Avaliação Qualitativa das Preparações do Cardápio Escolar (AQPC Escola) 33, que distribui os alimentos em "recomendados" e "controlados", selecionaramse alguns alimentos para controle nos cardápios: salsicha/linguiça, margarina, achocolatado e pudim/creme doce. Entende-se que a presença 
de qualquer um desses itens não deve exceder o limite de uma vez/semana ou quatro vezes/ mês. Os dois últimos itens (cálculo dos valores nutricionais dos cardápios e orientações para os alimentos comercializados nas cantinas) do indicador foram de fácil obtenção.

O segundo indicador - respeito à cultura alimentar saudável - suscitou dificuldade de entendimento no primeiro item (inserção de alimentos/preparações locais/regionais nos cardápios). Os respondentes muitas vezes ficaram reflexivos do que seria alimento regional. A despeito dessas dificuldades, um estudo que analisou a utilização de preparações regionais nos cardápios elaborados em 2007 para a alimentação escolar do ensino público brasileiro destacou a região Sul do país, onde $86 \%$ dos cardápios contemplavam pelo menos uma preparação regional por semana, vs. $38 \%$ no Norte 9 . O segundo item do indicador (atendimento adequado para povos e comunidades tradicionais) foi facilmente compreendido e o terceiro (investigação sobre os hábitos alimentares dos escolares) foi pouco discriminatório, apresentando o mesmo perfil de resposta nos casos. Apesar disso, o item será mantido, pois essa ação deve ser incentivada pelo seu poder de qualificar a adesão e a aceitabilidade ao Programa.

Quanto ao terceiro indicador - execução do cardápio - seus itens apresentaram comportamentos diferenciados conforme a gestão do PNAE. Nas gestões terceirizadas, substituições de cardápios não foram referidas como prática comum, ao contrário das respostas obtidas nas gestões centralizadas. De modo geral, constatouse a inexistência de instrumentos de gestão que dessem conta de responder ao indicador. Ressalta-se a necessidade do gestor municipal do PNAE dispor de ferramentas de controle, minimamente estruturadas, com dados sobre o cardápio executado e o quantitativo de refeições servidas diariamente nas escolas. Essas informações são de extrema importância para qualificar a prestação de contas do PNAE, subsidiar ações de planejamento e estímulo à adesão, e mostrar se as substituições de preparações necessitam de uma intervenção direta por parte da equipe de nutrição.

No último indicador - adequação dos cardápios para escolares que necessitam de atenção específica - foi observada dificuldade de compreensão por parte dos respondentes quanto à existência de cardápios adequados para atender a cada grupo de escolares com necessidades nutricionais especiais. Muitos consideraram esses cardápios como a oferta de alguns itens alimentares (por exemplo: leite de soja ou biscoitos sem glúten), o que não garante o direito humano à alimentação adequada dos estudantes. Em casos de execução terceirizada nem sempre os nutri- cionistas ligados à gestão tinham conhecimento dos itens oferecidos. Entende-se como dever da gestão dispor de cardápios específicos às condições de saúde dos escolares, buscando assegurar aos mesmos uma alimentação variada, saudável e adequada.

\section{Subdimensão Monitoramento Alimentar e Nutricional}

O primeiro indicador - vigilância nutricional dos escolares - apresentou desempenho ruim na grande maioria dos casos, devendo permanecer como forma de estimular a ação. Em nível local, a avaliação nutricional dos escolares alcança seus objetivos quando possibilita o cuidado e o direcionamento individual de cada estudante. Assim, a gestão deve ser organizada para obter os dados de todos os escolares sob sua responsabilidade, podendo ser esta uma atribuição de responsabilidade exclusiva da gestão do PNAE ou de responsabilidade compartilhada com outros atores/setores. Esses dados devem subsidiar as ações de planejamento e gestão do PNAE 2,3. No segundo indicador - supervisão do nutricionista - constatou-se diferentes comportamentos nos tipos de gestão do PNAE, embora isto deva ocorrer de forma equivalente e com a mesma importância em todas as modalidades. Entende-se que a equipe de nutrição deve visitar as escolas e orientar sobre o porcionamento no mínimo uma vez/mês (período usual de troca de cardápios).

\section{Subdimensão Atuação Pedagógica para a Alimentação Saudável}

O primeiro indicador - ações de estímulo à educação alimentar e nutricional - foi composto por dois itens, sendo que o segundo (quantitativo de escolas que desenvolvem atividades de incentivo à alimentação saudável) mostrou-se distante do campo de domínio da gestão. Todos os casos referiram não ter controle e/ou contatos sistemáticos com os atores escolares. Sabe-se que na área escolar muitas das ações de interesse devem ser observadas diretamente nas escolas, sendo inviável que a gestão esteja a par de todos os acontecimentos. Todavia, optou-se por manter esse item, partindo-se da premissa de que o monitoramento das práticas escolares de incentivo à alimentação saudável por parte dos gestores permite que estes planejem suas ações com base no panorama da rede, podendo rever suas prioridades conforme as demandas locais. Tal opção foi embasada também nos resultados de pesquisa com 670 municípios em 2004 e 2005, que observou que cursos de educação alimentar e nutricional aos alunos ainda não eram usuais entre as prefei- 
turas 4 . O segundo indicador - transversalidade do tema alimentação saudável - mostrou maior dificuldade no primeiro item (inserção do tema alimentação saudável no currículo escolar), uma vez que em metade dos casos os respondentes não tinham conhecimento da proposta curricular e a informação não foi facilmente obtida. Apesar disso, o indicador permanecerá no modelo nos moldes pensados, pois integra as normativas do PNAE 2,3. Considerando-se o papel chave dos professores nas ações cotidianas de estímulo à alimentação saudável, entende-se como importante estratégia de gestão a capacitação destes para trabalhar com a temática.

\section{Considerações finais}

O modelo avaliativo elaborado utiliza como base as normativas do PNAE, as quais estão em consonância com os aspectos propostos pela Política Nacional de Segurança Alimentar e Nutricional (PNSAN), e dispõem sobre as atribuições institucionais para execução do Programa. Essa primeira aplicação do instrumento demonstrou viabilidade na utilização dos indicadores propostos para contemplar as atribuições de responsabilidade da gestão municipal do PNAE. Alguns dados foram de difícil obtenção e atentam para lacunas importantes na gestão do Programa. Os resultados observados sugerem que todos os indicadores permaneçam no modelo, e que alguns ajustes podem ser feitos no decorrer de aplicações sucessivas para qualificar ainda mais a atuação da gestão.
O estudo evidenciou algumas tendências por parte das gestões municipais conforme modalidade de execução do PNAE. Como exemplo ressalta-se a dificuldade de obtenção de dados relativos à subdimensão Recursos quando as gestões eram terceirizadas. Por outro lado, na subdimensão Eficácia Alimentar e Nutricional deparou-se com a inexistência de alguns mecanismos de controle nas gestões centralizadas. Embora esse não fosse o objetivo deste trabalho, sugerem-se pesquisas futuras para aprofundamento dessas questões, uma vez que um programa público com o tamanho e a importância do PNAE deve manter seu padrão de qualidade e transparência, independentemente do tipo de sua execução local. Deve-se ressaltar também a provável interferência dos contextos locais na implementação do PNAE. Ainda que sejam municípios de porte semelhante, diversos elementos podem influenciar a dinâmica do Programa em nível local, devendo ser futuramente refletidos para subsidiar a interpretação dos achados.

Ainda que o PNAE date de longa existência, a ótica avaliativa nos permite considerá-lo como um programa "relativamente novo", uma vez que mostra um desenho bem diferenciado nos últimos anos. Esse perfil atual do Programa suscita desafios e demanda revisão de muitas ações por parte dos envolvidos no seu planejamento e execução. 


\section{Resumen}

Se presenta una propuesta de un modelo para evaluar la gestión municipal del Programa de Alimentación Escolar Brasileño (PNAE), probando su aplicabilidad en diez municipios de Santa Catarina, Brasil, con más de 100.000 habitantes. La construcción del modelo se produjo a través de experiencias con especialistas y su adecuación se logró mediante el método Delphi, con una participación de 14 colaboradores. El modelo incluyó dos dimensiones de la gestión municipal: dimensión político-organizacional, organizada en subdimensiones de recursos, actuación intersectorial y control social; y la dimensión técnico-operacional, que contempla las subdimensiones: eficacia alimentaria y nutricional, monitoreo nutricional y actividades educativas para una alimentación saludable. En total fueron incluidos 22 indicadores, recogidos a través de entrevistas con responsables del PNAE. En la evaluación de la aplicabilidad, los indicadores parecieron viables para evaluar las atribuciones de la responsabilidad municipal y el modelo se debería emplear para evaluar la gestión del PNAE.

Política Nutricional; Alimentación Escolar; Seguridad Alimentaria; Evaluación de Programas y Projectos de Salud

\section{Colaboradores}

C. G. Gabriel contribuiu com a concepção do projeto, coleta, análise, interpretação dos dados, redação do artigo e aprovação final da versão a ser publicada. M. C. M. Calvo contribuiu com a concepção do projeto, análise e interpretação dos dados, redação do artigo e aprovação final da versão a ser publicada. R. M. Ostermann contribuiu com a análise e interpretação dos dados, redação do artigo e aprovação final da versão a ser publicada. F. A. G. Vasconcelos contribuiu com a concepção do projeto, revisão crítica do artigo e aprovação final da versão a ser publicada.

\section{Agradecimentos}

A todos os gestores envolvidos e, em especial, aos nutricionistas do PNAE. Ao CNPq, pelo financiamento desta pesquisa.

\section{Referências}

1. Fundo Nacional de Desenvolvimento da Educação. Alimentação escolar. http://www.fnde.gov. br/programas/alimentacao-escolar/alimentacaoescolar-apresentacao (acessado em 05/Jan/2013).

2. Brasil. Lei no 11.947, de 16 de junho de 2009. Dispõe sobre o atendimento da alimentação escolar e do Programa Dinheiro Direto na Escola aos alunos da educação básica. Diário Oficial da União 2009; 17 jun.

3. Fundo Nacional de Desenvolvimento da Educação. Resolução no 38, de 16 de julho de 2009. https:// www.fnde.gov.br/index.php/ae-legislacao (acessado em 02/Jan/2013).

4. Belik W, Chaim NA. O Programa Nacional de Alimentação Escolar e a gestão municipal: eficiência administrativa, controle social e desenvolvimento local. Rev Nutr 2009; 22:595-607.
5. Gabriel CG, Costa LCF, Calvo MCM, Vasconcelos FAG. Planejamento de cardápios para alimentação escolar de alunos de escolas públicas municipais: reflexão e ilustração deste processo em duas capitais brasileiras. Rev Nutr 2012; 25:363-72.

6. Santos LMP, Santos SMC, Santana LAA, Henrique FCS, Mazza RPD, Santos LAS, et al. Avaliação de políticas públicas de segurança alimentar e combate à fome no período 1995-2002. 4 - Programa Nacional de Alimentação Escolar. Cad Saúde Pública 2007; 23:2681-93.

7. Pipitone MAP, Ometto AMH, Silva MV, Sturion GL, Furtuoso COM, Oetterer M. Atuação dos conselhos municipais de alimentação escolar na gestão do Programa Nacional de Alimentação Escolar. Rev Nutr 2003; 16:143-54. 
8. Sturion GL, Silva MV, Ometto AMH, Furtuoso COM, Pipitone MAP. Fatores condicionantes da adesão dos alunos ao Programa de Alimentação Escolar no Brasil. Rev Nutr 2005;18:167-81.

9. Chaves LG, Mendes PNR, Brito RR, Botelho RBA. O Programa Nacional de Alimentação Escolar como promotor de hábitos alimentares regionais. Rev Nutr 2009; 22:857-66.

10. Silva AV. Avaliação do Programa Nacional de Alimentação Escolar em âmbito municipal: subsídios para o desenvolvimento de uma metodologia [Dissertação de Mestrado]. Salvador: Programa de Pós-graduação em Alimentos, Nutrição e Saúde, Universidade Federal da Bahia; 2009.

11. Soares TMB. Uma proposta para análise do PNAE na perspectiva do direito humano à alimentação adequada: desenvolvimento metodológico e aplicação [Dissertação de Mestrado]. Salvador: Programa de Pós-graduação em Alimentos, Nutrição e Saúde, Universidade Federal da Bahia; 2012.

12. Carvalho CMP. Proposta de avaliação do Programa Nacional de Alimentação Escolar para municípios no Estado do Rio de Janeiro [Dissertação de Mestrado]. Salvador: Programa de Pós-graduação em Alimentos, Nutrição e Saúde, Universidade Federal da Bahia; 2012.

13. Figueiró AC, Frias PG, Navarro LM. Avaliação em saúde: conceitos básicos para a prática nas instituições. In: Samico I, Felisberto E, Figueiró AC, Frias PG, organizadores. Avaliação em saúde: bases conceituais e operacionais. Rio de Janeiro: Medbook; 2010. p. 1-13.

14. Bosi MLM, Uchimura KY. Avaliação de políticas e programas em alimentação e nutrição. In: Taddei JA, Lang RMF, Longo-Silva G, Toloni MHA, organizadores. Nutrição em saúde pública. Rio de Janeiro: Rubio; 2011. p. 411-22.

15. Instituto Nacional de Estudos e Pesquisas Educacionais Anísio Teixeira. Avaliação do PNAE - censo escolar 2004. http://download.inep.gov.br/down load/estudos_pesquisas/financ_gasto/pnae_rela torio2004_final.pdf (acessado em 15/Jan/2013).

16. Associação Brasileira de Nutrição. Pesquisa nacional do consumo alimentar e perfil nutricional de escolares, modelos de gestão e de controle social do PNAE. http://www.asbran.org.br/sitenovo/arqui vos/PainelAsbran14.pdf (acessado em 03/Jan/ 2013).

17. Linstone H, Turoff M. The Delphi Method: techniques and applications. http://is.njit.edu/pubs/ delphibook/ (acessado em 07/Dez/2012).

18. Brasil. Lei no 11.346 , de 15 de setembro de 2006. Cria o Sistema Nacional de Segurança Alimentar e Nutricional - SISAN - com vistas em assegurar o direito humano à alimentação adequada e dá outras providências. Diário Oficial da União 2006; 18 set.

19. Conselho Federal de Nutricionistas. Resolução CFN no 465, de 23 de agosto de 2010. http:/ / www. cfn.org.br/novosite/arquivos/Resol-CFN-465-atri buicao-nutricionista-PAE.pdf (acessado em 01/ Nov/2012).

20. Brasil. Lei no 6.514, de 22 de dezembro de 1977. Altera o Capítulo V do Título II da Consolidação das Leis do Trabalho. Diário Oficial da União 1977; 23 dez.
21. Agência Nacional de Vigilância Sanitária. Resolução RDC no 216, de 15 de setembro de 2004. Dispõe sobre Regulamento Técnico de Boas Práticas para Serviços de Alimentação. Diário Oficial da União 2004; 16 set.

22. Burlandy L. A construção da política de segurança alimentar e nutricional no Brasil: estratégias e desafios para a promoção da intersetorialidade no âmbito federal de governo. Ciênc Saúde Coletiva 2009;14:851-60.

23. Ministério da Saúde. Portaria interministerial no 1.010, de 8 de maio de 2006. Institui as diretrizes para a promoção da alimentação saudável nas escolas de educação infantil, fundamental e nível médio das redes públicas e privadas, em âmbito nacional. Diário Oficial da União 2006; 9 mai.

24. Brasil. Decreto o 6.286, de 5 de dezembro de 2007. Institui o Programa Saúde na Escola - PSE, e dá outras providências. Diário Oficial da União 2007; $6 \mathrm{dez}$.

25. Secretaria de Atenção à Saúde, Ministério da Saúde. Guia alimentar para a população brasileira: promovendo a alimentação saudável. Brasília: Ministério da Saúde; 2006.

26. Santa Catarina. Lei no 15.265 , de 18 de agosto de 2010. Autoriza o Poder Executivo a instituir o Programa de Prevenção e Tratamento da Obesidade Infantil nas instituições de ensino públicas e privadas do Estado de Santa Catarina. http://www. pmf.sc.gov.br/arquivos/arquivos/pdf/11_05_201 1_14.13.35.5f90e822e7ae6b3fb1e5bc59b147cb5a. pdf (acessado em 17/Nov/2012).

27. Takahashi MABC, Pizzi CR, Diniz EPH. Nutrição e dor: o trabalho das merendeiras nas escolas públicas de Piracicaba - para além do pão com leite. Rev Bras Saúde Ocup 2010; 35:362-73.

28. Carvalho AT, Muniz VM, Gomes JF, Samico I. Programa de alimentação escolar no Município de João Pessoa - PB, Brasil: as merendeiras em foco. Interface Comun Saúde Educ 2008; 12:823-34.

29. Federação Nacional de Nutricionistas. Tabela de honorários. http://www.fnn.org.br/tabela.php (acessado em 17/Nov/2012).

30. Mello AL, Vidal Júnior PO, Sampaio LR, Santos LAS, Freitas MCS, Fontes GAV. Perfil do nutricionista do Programa Nacional de Alimentação Escolar na Região Nordeste do Brasil. Rev Nutr 2012; 25:119-32.

31. Cardoso RCV, Góes JAW, Almeida RCC, Guimarães AG, Barreto DL, Silva SA, et al. Programa Nacional de Alimentação Escolar: há segurança na produção de alimentos em escolas de Salvador (Bahia)? Rev Nutr 2010; 23:801-11.

32. Triches RM, Schneider S. Alimentação escolar e agricultura familiar: reconectando o consumo à produção. Saúde Soc 2010; 19:933-45.

33. Veiros MB, Martinelli SS. Avaliação qualitativa das preparações do cardápio escolar - AQPC Escola. Nutrição em Pauta 2012; maio/junho:3-11.

Recebido em 20/Fev/2013

Versão final reapresentada em 15/Out/2013 Aprovado em 22/Mai/2014 